\title{
Effect of Tacrolimus Treatment on Tear Fluid Cytokines of Keratoconjunctivitis SICCA Affected Dogs
}

\author{
Akshay Kumar, Aswathy Gopinathan*, Kiranjeet Singh, R. Sasikala and C.R. Swapana \\ Division of Surgery, Indian Council of Agricultural Research-Indian Veterinary Research \\ Instistute, Izzatnagar, Barielly, Uttar Pradesh, India \\ *Corresponding author
}

\section{A B S T R A C T}

\begin{tabular}{|l|}
\hline Ke y w o r d s \\
$\begin{array}{l}\text { Keratoconjunctivitis } \\
\text { SICCA Affected } \\
\text { Dogs }\end{array}$ \\
\hline Article Info \\
\hline $\begin{array}{l}\text { Accepted: } \\
\text { 24 August } 2020 \\
\text { Available Online: } \\
\text { 10 September } 2020\end{array}$ \\
\hline \hline
\end{tabular}

The study was conducted to evaluate the effect of tacrolimus $0.1 \%$ ointment on the tear fluid cytokines during treatment of keratoconjunctivitis sicca in dogs. Total 35 pug dogs were screened and graded as normal, early and late KCS cases on the basis of schirmer tear test. The concentration of the IFN- $\gamma$ and immunohistochemistry (IHC) expression of MMP-9 were higher in KCS cases compared to normal cases. The effect of tacrolimus $0.1 \%$ ointment was studied on $16 \mathrm{KCS}$ cases out of 35 which were divided into two groups A1 and A2 having 8 animals in each. Eye drops carboxy-methyl-cellulose and gentamicin was used in group A1 and ointment Tacrolimus $0.1 \%$ and drop gentamicin in group A2. The tear production was significantly $(\mathrm{P}<0.05)$ improved in $\mathrm{A} 2$ (Tacrolimus $0.1 \%)$ group whereas western blot expression of MMP-9 was more in group A1 post treatment. The concentration of the IL- 8 and IFN-g was found to be decreased significantly $(\mathrm{P}<0.05)$ in A2 group post treatment. On the basis of results it was concluded that cytokines interferon- gamma (IFN- $\gamma$ ) and MMP-9 up-regulates in early and late stages of KCS and application of Tacrolimus $(0.1 \%)$ ointment decreases the level of cytokines IL-8, IFN- $\gamma$ and MMP-9 in KCS cases.

\section{Introduction}

Keratoconjunctivitis sicca (KCS), also known as dry eye syndrome, is a chronic ophthalmic disease resulting from deficiency of proteins/cytokines in the pre-corneal tear film (Berdoulay et al., 2005). There are different stages of the KCS like early, late and ulcerative or it can also be categorized as the mild, moderate and severe KCS (John et al., 2018). Clinically, KCS manifests as mucoid ocular discharge, conjunctival hyperemia, blepharospasm, recurrent corneal ulceration, corneal vascularisation, fibrosis, and eventual pigmentation (Berdoulay et al., 2005).

Increased levels of pro-inflammatory cytokines and MMPs have been observed on the ocular surface of patients with KCS in humans (Massingale et al., 2009). Patients with inflammatory diseases (dry eye, atopic keratitis, vernal keratitis) have demonstrated an increase in tear cytokines such as interleukin (IL- 1, IL-6, IL-8, tumor necrosis factor- alpha (TNF- $\alpha$ ), interferon- gamma (INF- $\gamma$ ) and MMP-9 (Ambroziak et al., 
2016). Different treatment protocols are being used for the treatment of the KCS in dogs. The immunosuppressive agent Tacrolimus is more effective then cyclosporine A (Tocci et $a l ., 1989)$ and also prevent the progression of the corneal pigmentation (John et al., 2018). Present the study was conducted to evaluate the role of tear cytokines in the onset and progression of KCS in dogs and to study the effect of tacrolimus $(0.1 \%)$ ointment on the cytokines level on KCS affected dogs.

\section{Materials and Methods}

This study was conducted at referral veterinary polyclinic of institute for clinical diagnosis and staging of KCS as normal, early and late on the basis of schirmer's strip test. KCS was assigned as early stage when STT reading was $\leq 15 \mathrm{~mm} / \mathrm{min}$ and disease progression was assigned as late stage when STT reading was $\leq 5 \mathrm{~mm} / \mathrm{min}$. Tear samples from healthy dogs with STT reading $\geq$ $20 \mathrm{~mm} / \mathrm{min}$ were collected as Normal (control). Analysis of cytokines (IFN- $\gamma$, IL-8 and MMP-9) levels in different stages and evaluation of the effect of tacrolimus $(0.1 \%)$ in the progression of KCS was studied. Detailed ophthalmic examination was carried out and recorded in each case. Parameters viz menace response, palpebral reflex, conjunctival hyperemia, ocular discharge, corneal clarity, corneal ulcer, corneal vessel length, corneal vessel density, corneal pigmentation area, corneal pigment density and STT were recorded in each case. Normal physiological parameters like heart rate, respiratory rate and rectal temperature were also recorded in all the cases.

Tear samples from normal, early and late KCS cases were collected by using the schirmer's strip. The strips were placed on the lower fornix of the each eye after folding the strip of filter paper ( $35 \mathrm{~mm} \times 5 \mathrm{~mm}$ ) at the notch and putting the folded portion between the cornea and lower eyelid. The strips were kept at $-60 \mathrm{C}$ in a autoclaved $0.5 \mathrm{ml}$ Eppendorf tube. For extraction of the tear fluid, $0.5 \mathrm{ml}$ Eppendorf tubes with schirmer strips were punctured at the bottom with a cannula. The tube was then placed in a larger $(1.5 \mathrm{ml})$ tube and centrifuged at maximum rpm $(14,000 \mathrm{rpm})$ for 30 minutes at $4^{\circ} \mathrm{C}$. The tear sample collected from normal, early and late cases were pooled.The tear samples were then treated with protease inhibitor and stored at $20^{\circ} \mathrm{C}$ until processing.

Tear samples collected from early and late KCS cases were processed. The level of cytokines (IFN-gama, IL-8 and MMP-9) in early and late KCS was evaluated by ELISA and western blotting. Total protein concentration in the pooled tear samples of early and late KCS measured by the BCA protein estimation kit (GeNei ${ }^{\mathrm{TM}}$, Bangalore) method using bovine serum albumin as the standard according to the manufacturer's protocol. Based on the protein concentration, the pooled tear samples of normal, early and late KCS were diluted to final concentration of $30 \mu \mathrm{g} / 10 \mu \mathrm{l}$ with sterile distilled water. The diluted samples were subjected to SDSPAGE following the standard protocol as per Sambrook and Russell (2006).

After electrophoretic protein separation, wet electroblotting (tank transfer) was followed as in figure 3. The gel and PVDF membrane (cat. no. IPVH00010, Merck) were sandwiched between the cathode and the anode of transfer assembly (Genei, Model: Electro Transfer Mini System, Cat No:106816GB, Bangalore) along with the sponge and Whatman filter papers. The polyacrylamide gels was equilibrated in transfer buffer (14.4g Tris base, $3.02 \mathrm{~g}$ Glycine and $100 \mathrm{ml}$ Methanol, and finally volume to 1lit. with distilled water) to remove electrophoresis buffer salts and detergents, and filter papers were also pre-wetted in 
transfer buffer. PVDF membrane was charged with absolute methanol. The cassette was clamped tightly after ensuring that no air bubbles are formed or trapped between the gel and the membrane. An electrical field was applied from either side through the electrodes. The protein transfer was allowed to run for 1 keeping the current within 250 mAs.

Quantitative detection of IFN- $\gamma$ and IL- 8 in tear samples was done by using sandwich ELISA (Geno biosciences Pvt Ltd unit of Geno Technology Inc. USA) using canine specific kit. Tissue sample from ocular tissue of early and late KCS cases were taken after the consent of the animal owners to perform immunohistochemistry. IHC was performed to localize the MMP-9 proteins.

Sixteen KCS cases out of 35 were divided into two groups A1 and A2 having 8 animals in each. Animals of group A1 were treated with eye drops carboxy-methyl-cellulose and gentamicin. In group A2 ointment Tacrolimus $0.1 \%$ and drop gentamicin was given 3 times a day continuously for 28 days. Clinical effect of drugs in both the groups was observed at 7 , 15 and 28 days post treatment. The effect of tacrolimus $(0.1 \%)$ on the progression of KCS was determined based on the clinical, photographic evaluation and analysis of the cytokines.

The data were analysed by using JMP 9.0 and Graphpad Prism software. The parametric data were analysed by using one way ANOVA and tukeys post test for the comparison at different time interval and between the group comparisons. The non parametric data were analysed by using Wilcoxon/kruskal wallis test and Dunn method used for joint ranking. A value $\mathrm{P}<$ 0.05 was considered to be statistical significant. All the graphs were prepared with Graphpad Prism.

\section{Results and Discussion}

Total 35 canine cases were diagnosed with KCS. The age of dogs ranged from 6 months to 11 years with a mean \pm S.E. value of $4.5 \pm 0.46$ years. Males were affected more (20) than females (15). In all the animals, both eyes were found affected with KCS. Early KCS cases were having good blink reflex, slight ocular discharge at medial canthus, mild conjunctival hyperemia, hazy cornea, no corneal vessels and slight corneal pigmentation. STT values ranged from 8 to 14 $\mathrm{mm} / \mathrm{min}$ with a mean \pm S.E. value of $11.05 \pm$ $0.41 \mathrm{~mm} / \mathrm{min}$.

Late KCS cases were having sluggish blink reflex, slight ocular discharge at medial canthus, mild to moderate conjunctival hyperemia, hazy cornea, no corneal vessels and dense corneal pigmentation (Table 1). Early KCS cases were having better blink reflex, less corneal pigmentation and significantly more tear production compared to late KCS cases (Table 1). STT values ranged from 0 to $7 \mathrm{~mm} / \mathrm{min}$ with a mean \pm S.E. value of $4.857 \pm 0.47 \mathrm{~mm} / \mathrm{min}$ and were significantly less compared to early KCS cases (Fig. 1).

The total tear protein level was higher in the tears collected from early and late KCS cases than tears of normal cases. The SDS-PAGE profile of tear proteins in normal, early KCS and late KCS was found that proteins of 14 $\mathrm{kDa}$ band were prominently expressed in early KCS compared to late KCS (Fig. 2).

Concentration of IFN-g was found significantly higher in the tears of early stages of KCS than healthy animals on ELISA readings (Fig. 3). Western blot analysis showed higher expression of MMP-9 in early and late KCS compared to normal cases (Fig. 4). The immunohistochemistry (IHC) expression of MMP-9 was more on in late 
KCS as compared to early KCS and there was sparse expression in the normal tissue samples (Fig. 5).

The effect of tacrolimus $(0.1 \%)$ on the progression of KCS was determined based on the clinical, photographic evaluation and analysis of the cytokines. In the clinical evaluation the menace response was significantly improved in both the groups. The ocular discharge and conjunctval hyperemia improved with tacrolimus $0.1 \%$ in A2 group.

Table.1 Different ocular parameter and cytokines level recorded in normal, early and late KCS cases

\begin{tabular}{|c|c|c|c|c|}
\hline S.No. & PARAMETERS & NORMAL & EARLY & LATE \\
\hline 1 & Menace reflex & Present & Present & Sluggish \\
\hline 2 & Ocular discharge & No & Slight ocular discharge & Slight ocular discharge \\
\hline 3 & $\begin{array}{l}\text { Conjunctival } \\
\text { hyperemia }\end{array}$ & No & Mild & Mild to moderate \\
\hline 4 & Corneal clarity & Clear & Hazy & Hazy \\
\hline 5 & Corneal vessels & No & No & No \\
\hline 6 & Corneal pigmentation & No & Slight & Dense \\
\hline 7 & STT (mm/min) & Greater than 15 & $\begin{array}{l}\text { Ranged from } 8 \text { to } 14 \\
\mathrm{~mm} / \mathrm{min} \pm \text { S.E } 11.05 \pm 0.41\end{array}$ & $\begin{array}{l}\text { Ranged from } 0 \text { to } 7 \mathrm{~mm} / \mathrm{min} \\
\pm \text { S.E } 4.857 \pm 0.47\end{array}$ \\
\hline 8 & SDS-PAGE & & Prominently expressed & \\
\hline 9 & IFN- $\gamma(\mathrm{pg} / \mathrm{ml})$ & $10.09 \pm 1.77$ & $29.43 \pm 2.73^{*}$ & $14.42 \pm 8.73$ \\
\hline 10 & IL-8 (pg/ml) & $10.09 \pm 1.77$ & $8.33 \pm 1.12$ & $8.58 \pm 1.77$ \\
\hline 11 & $\begin{array}{l}\text { Western } \\
\text { (MMP-9) }\end{array}$ & Less & More expression & Less \\
\hline 12 & $\begin{array}{l}\text { Immunohistochemistry } \\
\text { (IHC) of MMP-9 }\end{array}$ & $\begin{array}{l}\text { Sparse } \\
\text { expression }\end{array}$ & Less than late KCS & More expression \\
\hline
\end{tabular}

(*indicates the significant $(\mathrm{P}<0.05)$ value between the groups)

Fig.1 Mean \pm SE of Schirmer tear test values in the animals of early and Late KCS on the day of presentation. $(* *$ indicates significance when $\mathrm{p}<0.01$ )

SCHIRMER TEAR TESTING

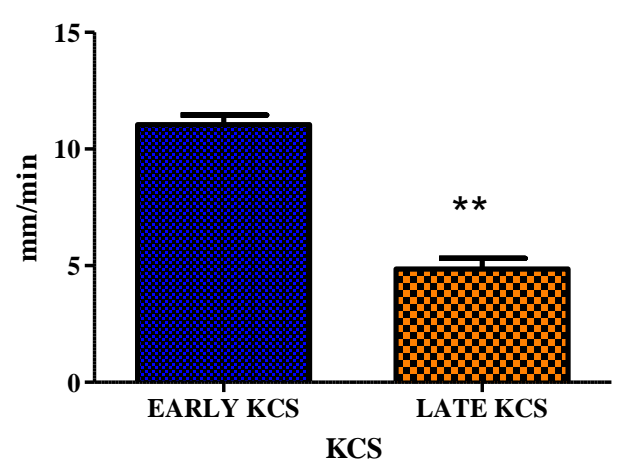

EARLY KCS

LATE KCS 
Fig.2 Coomasssie blue stained SDS-PAGE showing tear proteins of normal, early and Late KCS cases

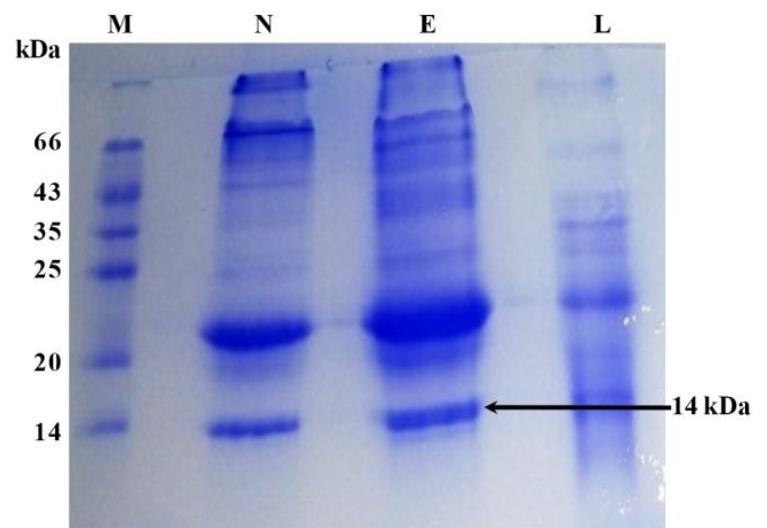

Lane M- prestained protein ladder, N-Pooled tear samples of normal animals, E- Pooled tear samples of early KCS, L- Pooled tear samples of late KCS

Fig.3 The concentration (pg/ml) of IFN- $\gamma$ in tear samples collected from normal, early and late KCS

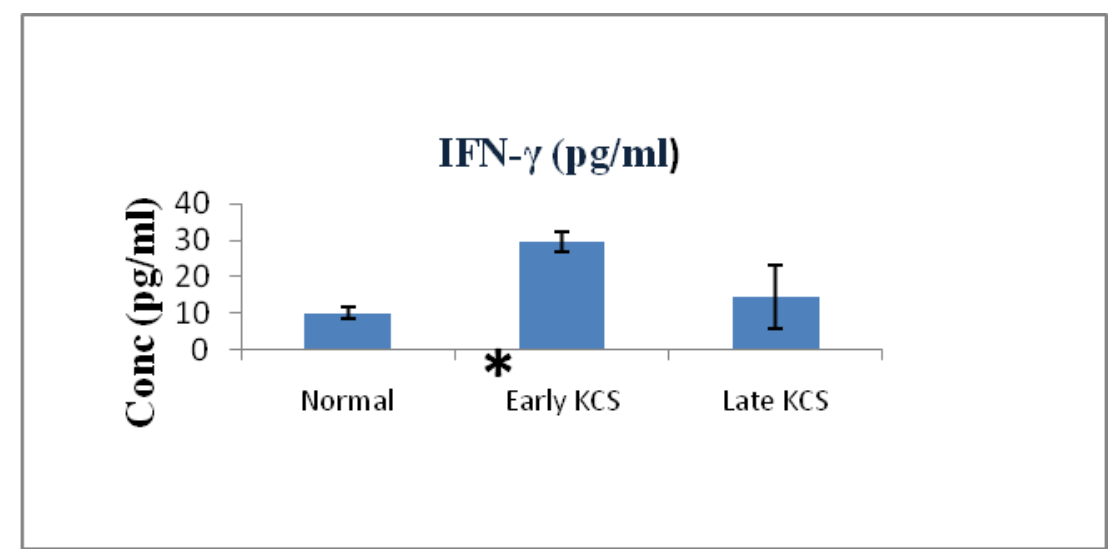

Fig.4 The picture showing expression of band on western blotting

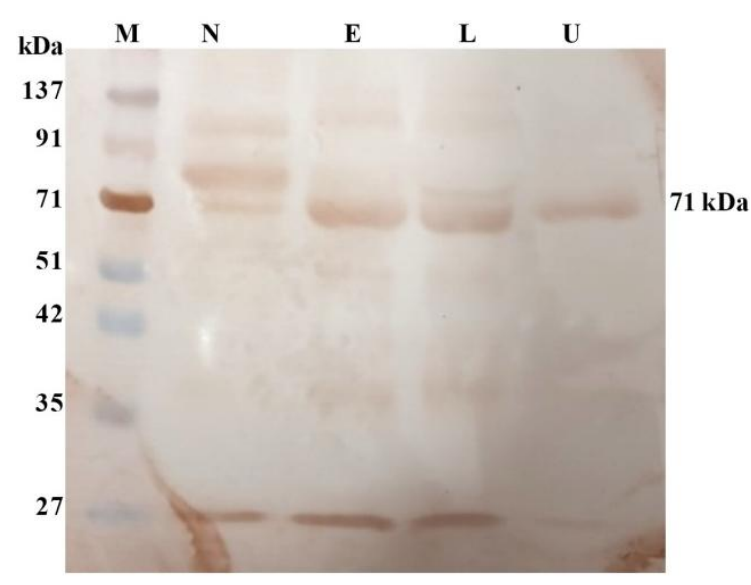


Fig.5 Showing the Immunohistochemistry expression of MMP-9 in normal (a), early (b) and late $\mathrm{KCS}$ (c) corneal tissue at $100 \mathrm{X}$
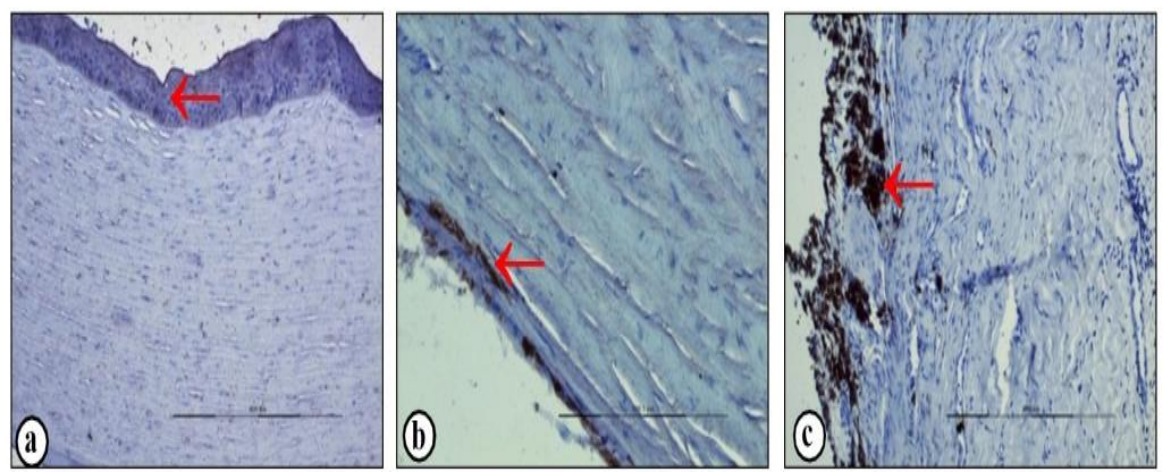

Fig.6 Tear production of groups A1 and A2 before and after 7, 15 and 28 days post treatment

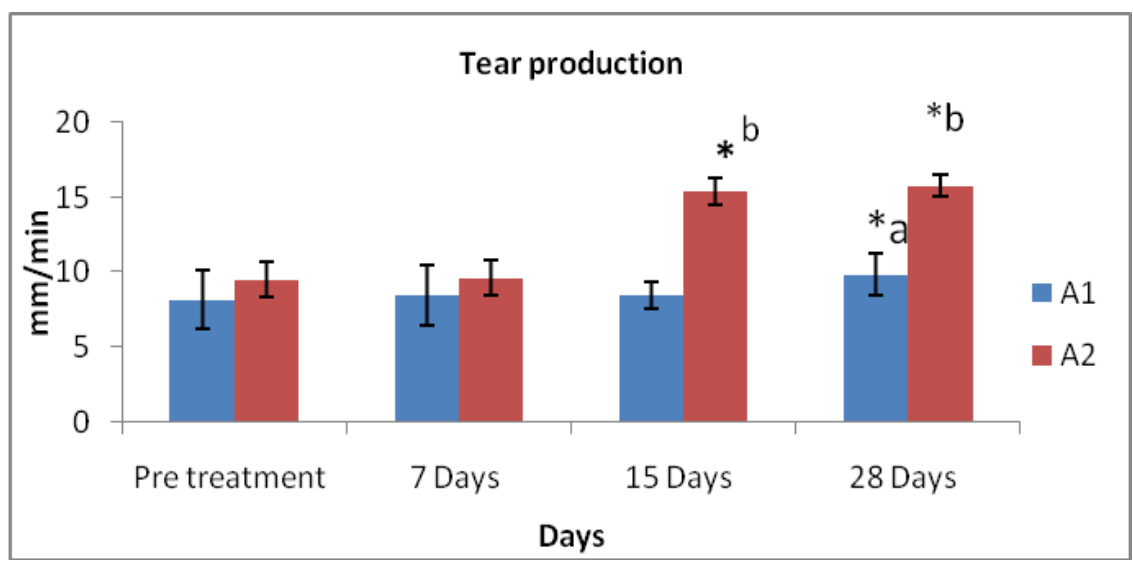

(Superscript * indicates significant $(\mathrm{P}<0.05)$ difference between the groups, whereas a and $\mathrm{b}$ indicates within the time intervals)

Fig.7 Concentration of the IL-8 before and after treatment in groups A1 and A2

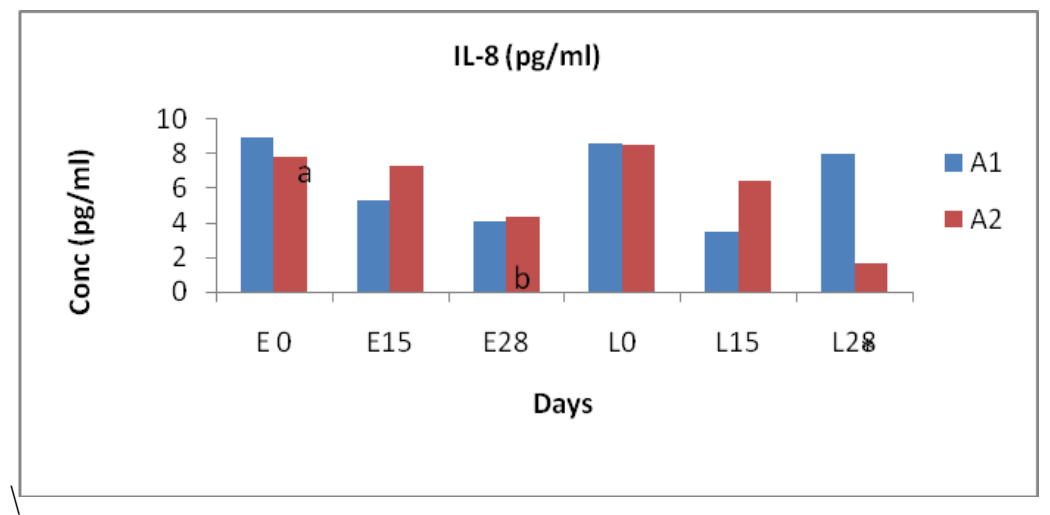

(Superscript * indicates significant $(\mathrm{P}<0.05)$ difference between the groups, whereas a and $\mathrm{b}$ indicates within the time intervals) 
Fig.8 Concentration of IFN- $\gamma$ before and after treatment in groups A1 and A2

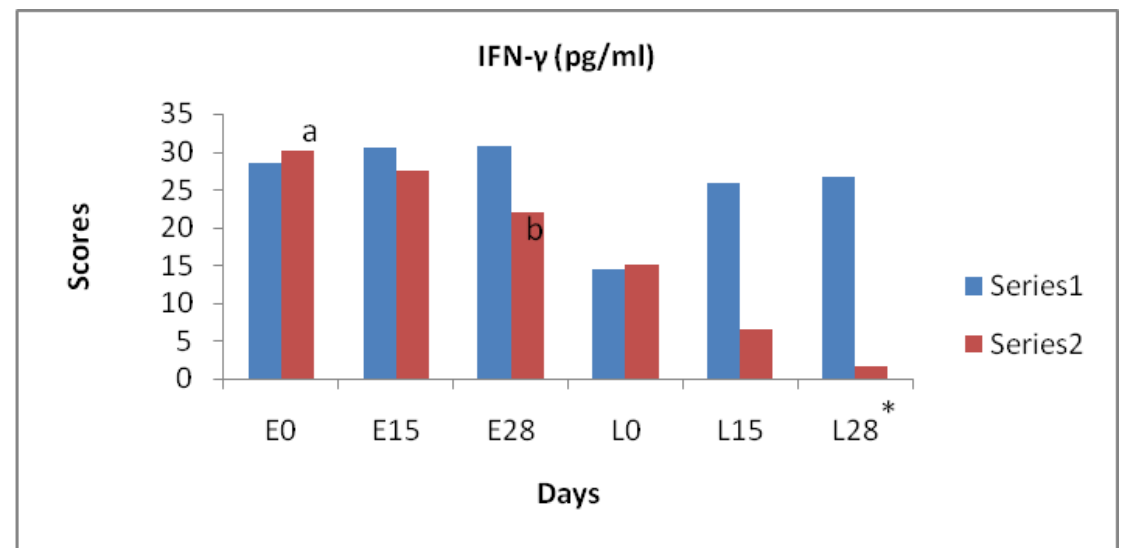

(Superscript * indicates significant $(\mathrm{P}<0.05)$ difference between the groups, whereas a and $\mathrm{b}$ indicates within the time intervals)

The improvement was noticed in the corneal clarity on day 28 post treatment from moderate opacity to hazyness in group A1. Slight decrease in the corneal vessel length and corneal vessel density was observed in group A2. The tear production was significantly $(\mathrm{P}<0.05)$ improved in $\mathrm{A} 2$ group as compared to group A1 (Fig. 6). Western blot analysis showed that expression of MMP-9 was more in group A1 post treatment than group A2 (Fig. 7). The concentration of the IL-8 and IFN-g was found to be decreased significantly $(\mathrm{P}<0.05)$ in $\mathrm{A} 2$ group post treatment than group A1 (Fig. 8).

In the present study, age group of 1-5 years (54\%) was affected more followed by 6-11 years $(37 \%)$ and 1 year (9\%). Animals of this age group are more playful and active in outdoor activities, hence more chance of exposure to sunlight and dust which explains its increased incidence. Similar age distribution of KCS was observed by John et al., (2018). Males were affected more (57\%) compared to females $(43 \%)$ in the present study. This distribution of gender may be due to increased male dog population in and around Bareilly region compared to females.

Both early and late KCS had almost similar scoring except for blink reflex, area of corneal pigmentation and Schirmer's tear test. Early KCS was having better blink reflex and less corneal pigmentation compared to late KCS. This is accordance to John et al., (2018) findings because the corneal pigmentation causes some hindrance to vision, the increased area of corneal pigmentation in late KCS may be the reason for their sluggish blink reflex. Late KCS cases had significantly less tear production compared to early KCS which corroborates the finding of John et al., (2018).

The total protein concentration in tear samples of early KCS (Mean \pm SE value of $18.10 \pm 7.652 \mu \mathrm{g} / \mu \mathrm{l})$ and late KCS (Mean \pm SE value of $18.92 \pm 4.916 \mu \mathrm{g} / \mu \mathrm{l})$ were higher compared to normal (Mean \pm SE value of $4.840 \pm 1.787 \mu \mathrm{g} / \mu \mathrm{l})$. Similarly, significantly higher tear protein level in KCS case has been reported (Disney, 2017). The increased protein concentration in KCS may be due to increased level of inflammatory mediators and decreased amount of tear production.

MMP-9 in dry eye cause apoptosis or programmed cell death of the ocular surface epithelia (Yeh et al., 2003). The protein expression levels of MMP-9 in the tear fluid from normal, early and late KCS cases were determined using western blotting analysis. 
Western blot analysis showed that expression of MMP-9 was more in early and late KCS compared to normal. Similarly the study conducted by Luo et al., (2004) recorded increased level of MMP-9 in dry eye disease. MMP-9 is an efficient activator of latent precursor cytokines and it is key inflammatory factor present in dry eye disease Luo et al., (2004).

Th- 1 cytokine interferon (IFN)- $\gamma$ is secreted exclusively by $\mathrm{T}$ cells (cytotoxic and Th-1) and natural killer cells. This cytokine plays a crucial role in vivo in regulating several immune responses, such as delayed-type hypersensitivity, inflammation, graft rejection, and the pathogenesis of inflammatory diseases (Sjögren's syndrome, mucus membrane pemphigoid, StevensJohnson syndrome, and graft-versus-host disease). Increased IFN- $\gamma$ can lead to conjunctival epithelial squamous metaplasia with progressive goblet cell loss It has been reported that the Th-1 cytokine IFN- $\gamma$, alone or combination with Fas ligand (FasL) and tumor necrosis factor (TNF)- $\alpha$, has a proapoptotic effect on some mucosal epithelial (Leaman et al., 2003).

IL-8 is an inflammatory cytokines, increased levels of IL-8 in the tear film and conjunctival epithelium, increased expression of immune activation and adhesion molecules (HLA-DR and intercellular adhesion molecule-1) by the conjunctival epithelium, and an increased number of $\mathrm{T}$ lymphocytes in the conjunctiva in both humans and animals (Jones et al., 1994). The IL-8 and IFN- $\gamma$ level were detected in normal, early and late KCS cases by using the canine specific ELISA kit which were based on the principal of sandwitch ELISA. It was observed that the concentration of the IFN- $\gamma$ was found significantly higher in the early stages of KCS than normal. It was also found increased in late stages of KCS but the level was not significantly higher than the normal stages. Results of our study corroborated with the finding of the study conducted by Brignole et al., (2001). Brignole et al., (2001) observed elevated level of IFN- $\gamma$ in the KCS. The concentration of IL-8 was found almost similar in both early and late stages of KCS it was slightly increased in normal tear fluid.

In clinical evaluation, menace response was found significantly improved in both the groups similar findings after treating $\mathrm{KCS}$ with tacrolimus was observed by John et al (2018). There was no change observed in the palpebral reflex scores in both the groups. The ocular discharge and conjunctval hyperemia improved with tacrolimus $0.1 \%$ in group A2. Slight decrease in the corneal vessel length and corneal vessel density was observed in group A2. Changes were not observed in the corneal pigmentation density and area of corneal pigmentation in both groups at different time interval after treatment. These findings are in accordance with the results reported by John et al., (2018). The improvement was noticed in the corneal clarity on day 28 post treatment from modertae opacity to hazyness in group A1 (carboxymethyl cellulose) the similar finding described by $\mathrm{Xu}$ and Wang (2018) by using the graft made of same material for the improvement of corneal transparency.

The tear production was significantly improved in group A2 as compared to group A1. Tacrolimus was found effective in increasing the tear production in animals of group A2 and results of our study corroborated the findings of research conducted by Berdoulay et al., (2005) and John et al., (2018).

Western blot analysis showed that expression of MMP-9 was more in group A1 post treatment than group A2. Tacrolimus was found effective to reduce the level of MMP-9 
in group A2 post treatment. Similarily, Sato et al., (2016) reported decrease in MMP-9 level after treating patients of acute encephalitis with refractory, repetitive partial seizures (AERRS) with tacrolimus.

The IL-8 and IFN- $\gamma$ are present in various inflammatory conditions. ELISA was performed in pre and post interval. The concentration of the IL-8 and IFN- $\gamma$ was found significantly decreased in group A2 than group A1 after treatment with tacrolimus. This decrease in the level of cytokines post treatment in group A2 may be due to the fact that Tacrolimus down regulates the secreations of pro inflammatory cytokines. Hanifin et al., (2005) also observed reduce level of cytokines after treating atopic dermatitis with Tacrolimus ointment.

From this study we concluded that cytokines interferon- gamma (IFN- $\gamma$ ) and MMP-9 upregulates in early and late stages of KCS and application of Tacrolimus $(0.1 \%)$ ointment decreases the level of cytokines IL-8, IFN- $\gamma$ and MMP-9 in KCS cases.

\section{Acknowledgments}

The authors acknowledge the scholars and scientific and technical staff of division of surgery and teaching veterinary clinical complex and referral veterinary polyclinic, ICAR-Indian Veterinary research institute, Izzatnagar, Bareilly, Uttar Pradesh, India, for providing necessary support and help at various levels for the study. This investigation was funded by the ICAR- Indian Veterinary Research Institute, Izzatnagar, Bareilly, Uttar Pradesh, India.

\section{References}

Ambroziak, A.M., Szaflik, J., Szaflik, J.P., Ambroziak, M., Witkiewicz, J. and Skopiński, P., 2016. Immunomodulation on the ocular surface: a review. Central-

European journal of immunology, 41(2):195.

Berdoulay, A., English, R.V. and Nadelstein, B., 2005. Effect of topical $0.02 \%$ tacrolimus aqueous suspension on tear production in dogs with keratoconjunctivitis sicca. Veterinary ophthalmology, 8(4):225-232.

Brignole, F., Pisella, P.J., De Saint Jean, M., Golds child, M., Goguel, A. and Baudouin, C., 2001. Flow cytometric analysis of inflammatory markers in KCS: 6-month treatment with topical cyclosporin A. Investigative ophthalmology \& visual science, 42(1):90-95.

Disney, JL., 2017. Tear lacritin concentrations in canine keratoconjunctivitis sicca. Master of Science, Virginia Polytechnic Institute and State University, Virginia.

Hanifin, J.M., Paller, A.S., Eichenfield, L., Clark, R.A., Korman, N., Weinstein, G., Caro, I., Jaracz, E., Rico, M.J. and US Tacrolimus Ointment Study Group., 2005. Efficacy and safety of tacrolimus ointment treatment for up to 4 years in patients with atopic dermatitis. Journal of the American Academy of Dermatology, 53(2):S186-S194.

John, C., Gopinathan, A., Singh, K., Sharma, P., Sowbharenya, C. and Sarangom, S.B., 2018. Clinical evaluation of topical tacrolimus ointment usage in different stages of keratoconjunctivitis sicca in dogs. Turkish Journal of Veterinary and Animal Sciences, 42(4):259-268.

Leaman, D.W., Chawla-Sarkar, M., Jacobs, B., Vyas, K., Sun, Y., Ozdemir, A., Yi, T., Williams, B.R. and Borden, E.C., 2003. Novel growth and death related interferon-stimulated genes (ISGs) in melanoma: greater potency of IFN- $\beta$ compared with IFN- $\alpha$ 2. Journal of interferon \& cytokine research, 23(12):745-756. 
Luo et al. (2004) Luo, L., Li, D.Q., Doshi, A., Farley, W., Corrales, R.M. and Pflugfelder, S.C., 2004. Experimental dry eye stimulates production of inflammatory cytokines and MMP-9 and activates MAPK signaling pathways on the ocular surface. Investigative ophthalmology \& visual science, 45(12):4293-4301.

Massingale, M.L., Li, X., Vallabhajosyula, M., Chen, D., Wei, Y. and Asbell, P.A., 2009. Analysis of inflammatory cytokines in the tears of dry eye patients. Cornea, 28(9):1023-1027.

Sambrook J and Russell DW., 2001. Commonly Used Techniques in Molecular Cloning. In Molecular Cloning, Volume 3, 3rd edition (eds. Sambrook and Russell). Cold Spring Harbor Laboratory Press, Cold Spring Harbor, NY, USA.

Sato, Y., Numata-Uematsu, Y., Uematsu, M., Kikuchi, A., Nakayama, T., Kakisaka, Y., Kobayashi, T., Hino-Fukuyo, N., Suzuki, H., Takahashi, Y. and Saito, Y., 2016. Acute encephalitis with refractory, repetitive partial seizures: Pathological findings and a new therapeutic approach using tacrolimus. Brain and Development, 38(8):772-776.

Tocci, M.J., Matkovich, D.A., Collier, K.A., Kwok, P., Dumont, F., Lin, S., Degudicibus, S., Siekierka, J.J., Chin, J. and Hutchinson, N.I., 1989. The immunosuppressant FK506 selectively inhibits expression of early $\mathrm{T}$ cell activation genes. The Journal of Immunology, 143(2):718-726.

Xu, W., Wang, Z., Liu, Y., Wang, L., Jiang, Z., Li, T., Zhang, W. and Liang, Y., 2018. Carboxymethyl chitosan/gelatin/hyaluronic acid blended-membranes as epithelia transplanting scaffold for corneal wound healing. Carbohydrate polymers, 192:240-250.

Yeh, S., Song, X.J., Farley, W., Li, D.Q., Stern, M.E. and Pflugfelder, S.C., 2003. Apoptosis of ocular surface cells in experimentally induced dry eye. Investigative ophthalmology \& visual science, 44(1):124-129.

\section{How to cite this article:}

Akshay Kumar, Aswathy Gopinathan, Kiranjeet Singh, R. Sasikala and Swapana, C.R. 2020. Effect of Tacrolimus Treatment on Tear Fluid Cytokines of Keratoconjunctivitis SICCA Affected Dogs. Int.J.Curr.Microbiol.App.Sci. 9(09): 3347-3356. doi: https://doi.org/10.20546/ijcmas.2020.909.416 